\title{
THE IMPACT OF OBESITY ON ENTHESES ASSESSMENT IN PATIENTS WITH SPONDYLARTHRITIS - A REAL WORLD STUDY
}

Filipe Oliveira Pinheiro ${ }^{1, \star}$, Pedro Madureira ${ }^{1}$, Maria Seabra Rato ${ }^{1}$, Diogo Guimarães da Fonseca ${ }^{3}$, Salomé Garcia ${ }^{1}$, Bruno Miguel Fernandes ${ }^{1}$, Ana Martins ${ }^{1}$, Daniela Santos Oliveira ${ }^{1}$, Frederico Rajão Martins ${ }^{2}$, Miguel Bernardes ${ }^{1}$, Lúcia Costa ${ }^{1}$

1.Centro Hospitalar Universitário de São João, Porto (Douro Litoral), Portugal; 2.Centro Hospitalar Universitário do Algarve, Faro (Algarve), Portugal; 3.Centro Hospitalar de Vila Nova de Gaia/Espinho, Vila Nova de Gaia (Douro Litoral), Portugal.

*Corresponding author: filipe.pinheiro92@gmail.com

\section{BACKGROUND}

Enthesitis is a classic characteristic of spondyloarthritis and its assessment can be performed using several indices, such as the Maastricht ankylosing spondylitis enthesitis score (MASES), the leeds enthesitis index (LEI) and the spondyloarthritis research consortium of Canada enthesitis index (SPARCC). Although there are some data on the role of obesity in the assessment of spondylarthritis activity, especially in patients taking TNF- antagonists, little is known about the impact on the assessment of entheses. The aim of this study is to determine whether obesity is associated with higher enthesis activity in patients with spondylarthritis.

\section{METHODS}

Cross-sectional study that evaluated patients diagnosed with spondyloarthritis, registered on the national database (Reuma. pt) platform, under biotechnological therapy, during their first evaluation after starting current bDMARD. Demographic, clinical and laboratory data were evaluated. Pearson correlation analyzes were performed between enthesitis indices and body mass index (BMI) values, comparison between obese (BMI > 30) and nonobese groups and enthesitis indices (Mann-Whitney $U$ ), and analysis of logistic regression to identify predictors of higher enthesitis rates.

\section{RESULTS}

A total of 273 patients were included in this study, 123 (45.1\%) of which were female. Sixty-four (23.4\%) were smokers and $45(16.5 \%)$ reported alcohol consumption during most/all days of the week. Regarding the bDMARDs performed, 57 (23.8\%) were taking golimumab, 54 (22.6\%) adalimumab, 52 (21.8\%) infliximab, 45 (18.8\%) etanercept, 18 (7.5\%) certolizumab , 11 (4.6\%) secukinumab and $2(0.8 \%)$ ustekinumab. They had a mean age of $49.0 \pm 10$ years, with a BMI of $23.9 \pm 4.1 \mathrm{~kg} / \mathrm{m} 2$, a median LEl of $0 \pm 2$, a median SPARCC of $1 \pm 4$ and a median MASES of $1 \pm 4$, with median ESR and median CRP of $30 \pm 32 \mathrm{~mm} / 1 \mathrm{sth}$ and $1.4 \pm 2.2 \mathrm{mg} / \mathrm{L}$, respectively. There was a moderate correlation between BMI and MASES (0.428, p < 0.001) and SPARCC (0.328, $p=0.005$ ), with no statistically significant correlation with LEl. Obesity patients had higher enthesitis indices in all indices used — MASES $2 \pm 5$ vs. $0 \pm 1, p<0.001$, SPARCC $2 \pm 5$ vs. $0 \pm 2, p=0.001$ and LEI $0 \pm 2$ vs. $0 \pm 1, p=0.049$. Logistic regression analyses allowed us to determine that obesity is associated with higher MASES (OR $=1,638,95 \% \mathrm{Cl}=1,225-2,191, p=0.001)$, regardless of age, gender, ESR and CRP, maintaining statistical significance when adjusted for those variables $(\mathrm{OR}=1,665,95 \% \mathrm{Cl}=1,315-2,108$, $p<0.001)$. This relationship was not obtained for the other indices.

\section{CONCLUSION}

In this sample, it was found that obesity is associated with higher enthesitis indices in patients with spondylarthritis, especially MASES, regardless of age, sex and inflammatory markers. In this regard, the authors emphasize the important role that musculoskeletal ultrasound can play in evaluating the involvement of entheses in patients with spondylarthritis, especially in obese patients.

\section{KEYWORDS}

Spondyloarthritis, Obesity, Enthesis. 